\title{
Justification and the knowledge-connection
}

\author{
Jaakko Hirvelä ${ }^{1}$
}

Accepted: 10 September 2021 / Published online: 7 October 2021

(C) The Author(s) 2021

\begin{abstract}
I will present a novel account of justification in terms of knowledge on which one is justified in believing $p$ just in case one could know that $p$. My main aim is to unravel some of the formal properties that justification has in virtue of its connection to knowledge. Assuming that safety is at least a necessary condition for knowledge, I show that justification (1) doesn't iterate trivially; (2) isn't a luminous condition; (3) is closed under a certain kind of multi-premise closure principle, but; (4) surprisingly one can nevertheless believe with justification a set of claims that's jointly inconsistent. This last feature allows for a rather satisfying solution to the preface paradox. Finally, I contrast my account with other knowledge-first accounts of justification.
\end{abstract}

Keywords Justification - Knowledge $\cdot$ Safety · Knowledge-first epistemology · Formal properties ofjustification · Preface paradox · Lottery paradox

\section{Introduction}

According to the lore, it was once held that knowledge is justified true belief. Gettier (1963) refuted the so-called justified true belief analysis of knowledge by demonstrating that a belief can be true and justified and yet fall short of knowledge. A score of epistemologists sought to save the classical analysis by offering new accounts of justification that wouldn't be susceptible to Gettier cases, while others tried to add more conditions that wouldn't be satisfied in Gettier cases. Many abandoned the notion of justification altogether and gave analyses of knowledge that didn't invoke justification.

Jaakko Hirvelä

jaakko.hirvela@helsinki.fi

1 Department of Philosophy, History and Art Studies, University of Helsinki, Helsinki, Finland 
I think that the third strategy is largely correct. Knowledge shouldn't be analyzed in terms of justification. Many externalists took a further step, and claimed that one can know that $p$ without being justified in believing that $p .{ }^{1}$ But here they erred. The fact that justification doesn't figure in the analysis of knowledge doesn't mean that there wouldn't be a tight connection between justification and knowledge. Even if knowledge isn't even partially constituted by justification, it can entail justification. In what follows, I propose an account of justification in terms of knowledge. I argue that the justificatory status of a belief depends on whether it could amount to knowledge. I call this the modal account of justification (MAJ). On this account, justification is a certificate that indicates that the belief or proposition in question could amount to knowledge. The account I propose secures a tight connection between knowledge and justification. It just reverses the traditional order of explanation. Justification is explained in terms of knowledge, not the other way around.

This account is knowledge first in that it takes knowledge to be both theoretically and metaphysically prior to justification. ${ }^{2}$ I hold that knowledge and safe belief are intricately connected. Very roughly, a subject is safe from error just in case she couldn't easily have believed something that's false. While I think that knowledge is safe belief, almost everything I say requires us only to accept that safety is necessary for knowledge. I don't assume that an analysis of knowledge in terms of safety would be reductive, though I'm not against the idea.

Before going into the details of MAJ, let me state a few reasons why it's promising. MAJ explains how and why justification is valuable. Justification is instrumentally valuable in that it serves to mark beliefs that have knowledge-like properties and its value derives from the value of knowledge. Secondly, it secures a tight connection between knowledge and justification but doesn't collapse one into the other, unlike some knowledge-first proposals. ${ }^{3}$ Thirdly, the view vindicates the idea that knowledge is the aim of belief. Beliefs that are justified are permissible in virtue of being such that they could amount to knowledge. If knowledge is the norm of belief, as many have argued, justification could be seen as a derivative norm of belief, since the function of justification is to guide us towards knowledge, which is the final aim. Most importantly, this proposal allows us to unravel several plausible formal principles that justification obeys. I will show that justification doesn't iterate trivially, that it's not a luminous condition, that Moore-paradoxical beliefs are never be justified, and that justification is closed under a certain kind of multi-premise closure principle. MAJ provides also an elegant solution to the preface and lottery paradoxes.

This paper is structured as follows. In Sect. 2 I lay out my positive proposal and clarify some key concepts. In Sect. 3 I highlight some formal principles that justification and knowledge obey. In Sect. 4 I compare MAJ with other knowledgefirst accounts of justification that have recently been proposed.

\footnotetext{
1 See Kornblith (2008), Foley (2012), Sylvan (2017) and Littlejohn (2018).

${ }^{2}$ Williamson (2000) is the foremost proponent of knowledge-first epistemology.

3 See Sutton $(2005,2007)$ and Williamson (forthcoming).
} 


\section{Turning tables}

Propositional justification pertains to the justificatory status that a proposition has for a subject, whereas doxastic justification is concerned with the justificatory status of the subject's beliefs. According to the standard story, whether a proposition $p$ is justified for $\mathrm{S}$ depends on whether $\mathrm{S}$ has good reasons to believe that $p$. The justificatory status of S's belief that $p$ depends on whether $\mathrm{S}$ believes that $p$ on the basis on which it's propositionally justified. Doxastic justification is defined in terms of propositional justification. ${ }^{4}$

In what follows, I won't talk of 'reasons', but of 'ways of believing'. 'There are three reasons for this. Firstly, 'ways of believing', unlike 'reasons', isn't a normative notion. Although I don't aspire to reduce justification to the non-normative, it would be good if the definition didn't invoke any other normative notions than knowledge. Secondly, it seems that some beliefs are justified, even though they aren't based on reasons. I can know that my legs are crossed, but it doesn't seem like this knowledge is based on prior reasons or evidence (Anscombe, 1962).

I won't engage with the question of how ways of believing should be individuated. While the question how ways of belief-formation should be individuated is an important one, I won't attempt to sketch an answer, nor do I think one is needed on this occasion. Firstly, the 'generality problem' applies in one form or another to virtually any theory of knowledge or justification. ${ }^{5}$ The problem is hardly unique to my view. Secondly, theories of knowledge or justification that suffer from the generality problem deliver different verdicts regarding certain cases depending on how ways of belief-formation are individuated. One of the key reasons for attempting to solve the generality problem is to secure an answer that yields intuitive verdicts in a principled way regarding different cases. Here I'm less concerned with intuitions that philosophers have regarding different cases since my aim is to have a firmer grip on some structural features of justification.

When it comes to the relationship between doxastic and propositional justification, I deviate from the standard account. To be propositionally justified in believing that $p$ is to be in a situation in which there's a way of believing that $p$ available to you, and believing that $p$ in that way yields knowledge that $p$ in some relevant possible world. To be doxastically justified in believing that $p$ one must believe that $p$ in a way that yields knowledge of $p$ in some relevant possible world. The account I offer is able to side step the so-called basing problem, since doxastic justification doesn't require that one base one's belief on the reasons that propositionally justify it. Rather, it's enough that one believes in a way that could yield knowledge.

In saying that a way of believing is available to a subject, I mean that the subject could easily enough believe some proposition in that way, in her current situation. For instance, I could easily enough believe that my coffee cup is empty in virtue of remembering that I just drank the last drops of coffee in it. Or I could easily enough

\footnotetext{
${ }^{4}$ See Firth (1978, p. 218), Kvanvig (2003), Lasonen-Aarnio (2010a, p. 206). For a critique of understanding doxastic justification in terms of propositional justification, see Turri (2010). For a response see Silva (2015).

5 See Comesana (2006) for an argument that the generality problem generalizes beyond reliabilism.
} 
believe that my legs are crossed when sitting legs crossed. I couldn't easily enough know how many biscuits are in the jar in my current situation, since the jar is in the cupboard and I'm taking a bath. I could of course easily get up, go to the kitchen and count the biscuits. But then I would no longer be in my current situation. Minimally, in order to remain in one's current situation one cannot go about gathering more evidence. $^{6}$

The fact that a way of believing is available to you in your current situation doesn't entail that it would be effortless for you to use that way of believing. Someone who finds logical reasoning hard, and often fails to succeed in it, could still easily enough have performed a competent deduction if she knows all the premises and the relevant rules of inference. The fact that she tends to fail in similar tasks, and that it takes great effort for her to succeed in competently deducing the conclusion, doesn't entail that she couldn't easily have done so.

It's worth to contrast this approach with evidentialism, according to which propositional justification is a function of evidential support. Whether a proposition is justified for $\mathrm{S}$ depends on how much the evidence that she has supports the proposition (Feldman \& Conee, 1985). Evidentialism is often understood in probabilistic terms: a proposition $p$ is justified for $\mathrm{S}$ just in case the probability of $p$ given S's entire body of evidence $\mathrm{E}$ is high enough. This feature of evidentialism makes the subject's cognitive capacities superfluous when it comes to propositional justification. On evidentialism, all necessary truths are propositionally justified for me since their probability is 1 on any body of evidence. But some necessary truths might be so complex that I'm psychologically incapable of believing them, and therefore I shouldn't have propositional justification to believe them. Evidentialism entails that propositional and doxastic justification come radically apart in that there are propositions that one is trivially propositionally justified to believe, but couldn't be doxastically justified to believe in. It's hard to see why propositional justification would always be valuable if we cannot even in principle tap into it due to our cognitive limitations in some cases. ${ }^{7}$

MAJ doesn't share this problem. On MAJ, I'm not trivially propositionally justified to believe all complex necessary truths, since whether those truths are propositionally justified for me depends on whether there's a way of believing those truths available for me that would yield knowledge. The key idea here is that propositional justification is something we can feasibly act on. It's not about what propositions are supported by one's evidence, but rather about the propositions one could know. That's why we care about propositional justification.

I hold that knowledge is intricately connected with safe belief. A belief is safe just in case it couldn't easily have been false. There are many competing proposals on how to make this condition explicit. ${ }^{8}$ Here I opt for the following formulation:

\footnotetext{
${ }^{6}$ I'd like to thank an anonymous reviewer at Philosophical Studies for inviting me to be more explicit here.

7 I'd like to thank Giada Fratantonio for helpful discussion.

${ }^{8}$ See, for instance Sosa (1999), Williamson (2000, 2009b), Lasonen-Aarnio (2010b), and Pritchard (2005, 2012). For arguments against the safety condition on knowing, see Neta and Rohrbaugh (2004), Bogardus (2014), and Miracchi (2015).
} 
SAFETY: S's belief that $p$, which belongs to a set of propositions $Q$, is safe if, and only if,

in all of closest possible worlds where $\mathrm{S}$ believes a proposition that belongs to

$Q$ in the way in which she actually believes that $p$, her belief is true. 9

The space of possible worlds is centred on the actual world and branches out according to a similarity ordering. The worlds that are closer to the actual world are more similar to it and represent possibilities that could easily have obtained. Worlds further away are less similar, and represent possibilities that couldn't easily have been realized. The worlds we're quantifying over are centred on a subject and a time, and they are metaphysically possible worlds, rather than epistemically possible worlds. In other words they are cases (Williamson, 2000, p. 52). ${ }^{10}$

SAFETY is relativized to the way of believing that the subject uses in the actual world and globalized to a set of propositions. This is standard practice with modal conditions for knowledge. ${ }^{11}$

The idea behind SAFETY is that in order to know one must be safe from error. SAFETY can adequately deal with Gettier cases and with more complicated cases (Pritchard, 2005). If knowledge is safe belief, skeptical hypotheses don't threaten our knowledge, since such hypotheses obtain only in far-away possible worlds, which are irrelevant when considering whether a belief is safe.

\footnotetext{
9 So-called 'weak' safety conditions-that require only that the subject's belief is true in most of the closest possible worlds-are not factive. If knowledge required only weak safety, then knowledge wouldn't be factive either. Sosa (2015) has expressed sympathy towards weak safety. For discussion of the kind of safety condition Sosa endorses, see (Hirvelä \& Paterson, 2021; Hirvelä, 2020b). The safety condition I endorse is a 'strong' safety condition, since it requires that the subject's belief has to be true in all of the closest possible worlds in order to be safe. Since each world is maximally close to itself, strong safety requires that the subject's actual belief is true. Proponents of 'strong' safety include Williamson (2000) and Lasonen-Aarnio (2010b) among others. I'd like to thank an anonymous reviewer at Philosophical Studies for encouraging me to be clearer on this front.

${ }^{10}$ For centred worlds see Lewis (1979, p. 531).

11 See Nozick (1981, pp. 184-185), Williamson (2000, p. 128) and Pritchard (2005) for relativizing modal conditions to the way in which the subject actually believes. See Hirvelä (2019a, p. 1182); Pritchard (2012, pp. 256-257); Sosa (2015, pp. 52-53, 123) and Williamson (2009b, p. 325) for globalizing the condition to a set of propositions. One of the reasons why safety-theorists globalize safety conditions to a set of propositions is that it allows them to explain the fact that a subject who believes a proposition that is necessarily true doesn't trivially know the proposition. For example, if S correctly guesses that $p$, where $p$ is an arithmetic truth, $\mathrm{S}$ doesn't thereby know it. SAFETY is not satisfied in such a case since the subject could easily have ended up believing a relevant proposition that is false via guessing. Notice that to deliver this verdict the set of propositions $Q$ cannot be restricted to contain only truths. How should the relevant set of propositions then be restricted? Safety-theorists differ in their answer to this question. Williamson (2009b, p. 325) holds that all of the relevant propositions have to be 'close' to each other. Pritchard (2012, pp. 256-257) thinks that the way of believing will restrict the set of propositions in an adequate way. I hold (Hirvelä, 2017, 2019a, 2020a) that the set of propositions should be restricted in terms of the subject's subject matter of inquiry and the way in which the subject believes the proposition. What we care about is whether the subject could easily have ended up with a false belief in her inquiry. But here we don't have to take sides. The different options have been laid out for the convenience of the reader. I'd like to thank an anonymous reviewer at Philosophical Studies for inviting me to lay out different ways in which safety-theorists can populate the set of relevant propositions $Q$.
} 
Though SAFETY is perhaps the most widely accepted substantial condition on knowing, it's controversial. While many accept the necessity of SAFETY, some are suspicious of the sufficiency of the condition. One set of potential counterexamples to the sufficiency of SAFETY build on the idea that some ways of believing are intuitively not knowledge-conducive, though they might yield safe beliefs due to a quirk of nature. If, unbeknownst to me, I'm a perfectly reliable clairvoyant, then the beliefs that I gain through clairvoyance are safe, but intuitively they might not be knowledge. ${ }^{12}$ If justification is potential knowledge, and SAFETY is sufficient for knowledge, then beliefs formed via clairvoyance, or via some other intuitively bad method, such as tea leaf reading, that due to a quirk of nature happen to yield a safe belief in some world, can yield justified beliefs, which seems unintuitive. ${ }^{13}$

Although I am of the opinion that SAFETY, or something very close to it, gives both the necessary and sufficient conditions for knowledge, for present purposes the claim that SAFETY is necessary for knowledge suffices. All but one of the formal properties of justification that I examine can be derived by assuming that SAFETY is merely a necessary condition for knowledge. If SAFETY exhausts the structural properties of knowledge, while nevertheless being insufficient for knowledge, then we can also prove that justification is closed under a certain kind of multi-premise closure principle. If SAFETY doesn't exhaust the structural properties of knowledge then understanding knowledge in terms of SAFETY can be understood as an idealization. Those who are skeptical of both the necessity and sufficiency of SAFETY can read what follows as an exploration of the question of "what kind of formal properties would justification have if knowledge was safe belief and justification potential knowledge?" I contend that understanding the formal properties of potential safety would in itself be a significant result. In ideal circumstances the formal properties that the framework yields are so welcome that those who are skeptical of SAFETY will reconsider its merits.

With these things in mind let me offer the following definitions of propositional and doxastic justification.

$\mathrm{JUST}^{\mathrm{P}}$ : A proposition $p$ is justified for $\mathrm{S}$ if, and only if:

(i) there's a way of believing that $p$ available to $\mathrm{S}$ and believing that $p$ in that way yields knowledge that $p$ in some possible world.

JUST $^{\mathrm{D}}: \mathrm{S}$ 's belief that $p$ is doxastically justified if, and only if,

(ii) there's a possible world where $\mathrm{S}$ knows that $p$ in the way that she actually believes that $p$.

\footnotetext{
${ }^{12}$ Bonjour (1980) introduced clairvoyance cases as counterexamples to process reliabilism, but they work more generally against any purely externalist theory of justification. Srinivasan (2020) has disputed the claim that clairvoyants are not justified in their beliefs. I argue elsewhere (Hirvelä, 2020a, p. 4074) that proponents of safety can deal with clairvoyant-style cases by relativizing the safety condition to virtuous ways of believing.

${ }^{13}$ I would like to thank two anonymous reviewers at Philosophical Studies for pressing this kind of worry.
} 
Both conditions require that $p$ is known in some possible world. The only restrictions on the relevant worlds is, in case of $\operatorname{JUST}^{\mathrm{P}}$, that $\mathrm{S}$ believes that $p$ in a way that's available for her in the actual world, and in the case of $\operatorname{JUST}^{\mathrm{D}}$, that the subject believes $p$ in the same way as she believes that $p$ in the actual world. This entails that the fact that $\mathrm{S}$ knows that $p$ in a faraway possible world can render S's belief justified in the actual world. Does this make the justification conditions too lenient, in that justification is all too easy to gain?

There's reason to think that merely justified beliefs could easily have amounted to knowledge. For instance, it seems that in Gettier cases one could easily have acquired knowledge if things had been slightly different (Sutton, 2007, p. 360; Zagzebski, 1994, p. 66). In such cases bad epistemic luck prohibits the subject from knowing, while good epistemic luck ensures that the subject's belief is nevertheless true. If Pritchard (2005) is right in claiming that an event is lucky just in case it could easily not have occurred, and it's just a matter of bad luck that one doesn't know in a Gettier case, then there must be a close enough world where one isn't Gettiered, and consequently acquires knowledge.

But Gettier cases aren't the only cases that feature merely justified beliefs. Many hold that a brain-in-a-vat (BIV) is justified in her beliefs. This is so, even though there's no close world where the BIV's belief that she has hands amounts to knowledge. The world where she knows that she has hands is a faraway possible world.

Depending on how ways of believing are individuated, MAJ can deliver the result that the BIV is justified in believing that she has hands. If the BIV believes that she has hands in the same way in the world where she is in the vat, and in the world where she isn't envatted, then her belief is justified. I suspect that internalists would want to individuate ways of believing in such a way that we and our BIV counterparts believe in the same way. Externalists can opt for an individuation principle that doesn't allow for this. Alternatively, externalists may restrict the domain of quantification to close worlds, so that $\mathrm{S}$ would be justified to believe that $p$ just in case there's some close world where the subject knows that $p .{ }^{14}$ This is my preferred way of understanding MAJ since I think that the new evil demon intuition is dispensable (in fact I don't have the intuition). ${ }^{15}$ That said, I'll focus on the conditions as given above, since that way we can stand on neutral ground with respect to the debate between internalism and externalism. ${ }^{16}$

\footnotetext{
14 Those externalists who are sympathetic to contextualism about justification might hold that the attributor's context determines the domain of quantification. If BIV-possibilities are contextually relevant the domain of quantification is larger, than in ordinary contexts where skeptical scenarios aren't relevant. I'd like to thank Daniel Drucker for discussion on this point.

15 This way of unpacking MAJ allows the externalist to accommodate the idea that some ways of believing that could yield safe beliefs only in faraway possible worlds due to a quirk of nature, such as tea leaf reading, cannot yield justified beliefs in the actual world. In my mind it is a virtue of MAJ that the general framework can be steered towards internalism or externalism while keeping the structural properties of justification intact.

${ }^{16}$ I should note that many of the formal properties of justification that MAJ entails, are widely endorsed by externalists, and shunned by internalists. I think that fact that such formal properties can be delivered
} 


\section{Formal properties of justification}

What kind of formal properties does justification have given the kind of connection that I have claimed holds between knowledge and justification?

Apart from factivity, SAFETY has two formal properties that are of special interest to us. Firstly, SAFETY doesn't iterate trivially. The fact that S knows that $p$ doesn't entail that she safely believes that she knows that $p$. This is because in order for S to be safe in her inquiry, it must be the case that she doesn't end up with a false belief in any of the closest worlds. In order for her belief that she knows that $p$ to be safe from error, it must be the case that she is safe from error in all of the closest worlds where she believes that she knows that $p$. This is much more demanding than first-order safety, which requires only that S's belief is safe in the actual world. Safely believing that one knows requires that one is safe from error in a larger set of worlds than just being safe from error requires. If knowledge requires SAFETY, then the KK-principle is false. Knowing that $p$ doesn't entail that one knows that one knows that $p$.

The second interesting property that SAFETY has is that it's closed under multipremise closure:

$\mathrm{MPC}^{\mathrm{K}}$ : If $\mathrm{S}$ knows $p_{1}, \ldots, p_{\mathrm{n}}$, competently deduces $q$ from $p_{1}, \ldots, p_{\mathrm{n}}$ and thereby comes to believe that $q$, while retaining knowledge of $p_{1}, \ldots, p_{\mathrm{n}}$ throughout, $\mathrm{S}$ knows that $q .{ }^{17}$

It's easy to see that SAFETY vindicates this principle. If $\mathrm{S}$ safely believes that $p_{1}$, $\ldots, p_{\mathrm{n}}$, then $p_{1}, \ldots, p_{\mathrm{n}}$ is true in all close possible worlds where $\mathrm{S}$ believes that $p_{1}$, $\ldots, p_{\mathrm{n}}$ in the way she actually believes $p_{1}, \ldots, p_{\mathrm{n}}$. Given that $\mathrm{S}$ competently deduces $q$ from $p_{1}, \ldots, p_{\mathrm{n}}, q$ is logically entailed by $p_{1}, \ldots, p_{\mathrm{n}}$. Otherwise it wouldn't be a competent deduction (Hirvelä, 2019b). Therefore $q$ is true in all worlds where $p_{1}$, $\ldots, p_{\mathrm{n}}$ is true. Hence, if $\mathrm{S}$ competently deduces $q$ from known premises then $q$ is true in all of the closest possible worlds where it's competently deduced from the known premises.

With these things in mind let us turn to examine the relationship between justification and SAFETY. A key difference between the justification conditions and SAFETY is that SAFETY demands that the subject has to avoid error in all of the closest cases, whereas the justification conditions demand that $\mathrm{S}$ safely believes the target proposition in some case. To explore the formal relations of the conditions, let me introduce the following model.

A model is a tuple $<W, R^{P}, R^{D}, R^{K}>$, where $W$ is a set, informally conceived as comprising of metaphysically possible worlds, $R^{P}, R^{D}$ and $R^{K}$ are accessibility relations between members of $W$. We have three different accessibility relations.

\footnotetext{
Footnote 16 continued

within a framework that is neutral between internalism and externalism provides an indirect argument for externalism, which is not grounded in our intuitions about disputed cases.

17 Proponents of MPC $^{\mathrm{K}}$ include Vogel (1990), Feldman (1995), Williamson (2000, 2009a), Hawthorne (2005), and Levi (2012). For dissenters, see Nozick (1981), and Dretske (2005).
} 
The accessibility relation for propositional justification, $R^{P}$, has access to all worlds where $\mathrm{S}$ believes in some way that is available to her in the evaluation world. $\mathrm{J}^{\mathrm{P}}(p)$ denotes that $p$ is propositionally justified, and $\mathrm{K}(p)$ that $p$ is known. $\operatorname{JUST}^{\mathrm{P}}$ can then be expressed as follows:

$$
w \models \mathrm{J}^{\mathrm{P}}(p) \text { iff }: \exists<w, w^{*}>\in R^{P}, w^{*} \models \mathrm{K}(p)
$$

For doxastic justification we need to make a slight alteration to the accessibility relation, since we're interested only in the worlds where $\mathrm{S}$ believes that $p$ in the way in which she actually believes that $p$. Therefore $R^{D}$ has access to all worlds where $\mathrm{S}$ believes in the way in which she believes in the evaluation world. $\mathrm{JUST}^{\mathrm{D}}$ is then formalized as follows:

$$
w \models \mathrm{J}^{\mathrm{D}}(p) \text { iff }: \exists<w, w^{*}>\in R^{D}, w^{*} \models \mathrm{K}(p)
$$

In formalizing SAFETY we follow Williamson (2009a, p. 24). This time the accessibility relation $R^{K}$ is a ternary relation $<w, w^{*}, f>$ where $w$ and $w^{*}$ are members of $W$ and $f$ is a function that maps formulas of the language to formulas of the language. The idea behind function $f$ is that it picks out all the propositions that $\mathrm{S}$ could have believed that are relevant when assessing whether $\mathrm{S}$ knows that $p$ in the evaluation world. In other words, $f$ picks out $p$ 's relevant counterparts. ${ }^{18}$ Moreover, $R^{K}$ has access only to the closest worlds where $\mathrm{S}$ believes in the way she believes in the evaluation world. Hence we get:

$$
w \models \mathrm{K}(p) \text { only if }: \forall<w, w^{*}, f>\in R^{K}, w^{*} \models f(p)
$$

All the accessibility relations are understood as reflexive. That is, for each $R$ and all worlds $w,<w, w>\in R$. Since closeness isn't a transitive relation $R^{K}$ is understood as a non-transitive relation. That is, $\left.\left\langle w, w^{*}\right\rangle \in R^{K} \&<w^{*}, w^{* *}\right\rangle \in R^{K}$ doesn't entail that $\left\langle w, w^{* *}\right\rangle \in R^{K}$.

Some knowledge-first views entail that justification is factive (Littlejohn, 2011; Sutton, 2005; Williamson, forthcoming). On MAJ neither doxastic nor propositional justification is factive.

Proof Suppose that $w \models \mathrm{J}^{\mathrm{P}}(p) \& \mathrm{~J}^{\mathrm{D}}(p)$. This entails that $\exists<w, w^{*}>\in R^{P}, w^{*} \models$ $\mathrm{K}(p) \& \exists<w, w^{* *}>\in R^{D}, w^{* *} \models \mathrm{K}(p)$. Suppose that $w^{*}=w^{* *} . w^{*} \models \mathrm{K}(p)$ if, and only if $\forall<w^{*}, w^{* *}, f>\in R^{K}, w^{* *}=f(p)$. Suppose that $w$ isn't among the worlds that are closest to $w^{*}$. Therefore it's possible that $\forall<w^{*}, w^{* *}, f>\in R^{K}, w^{* *}=$ $f(p) \& \exists<w^{*}, w, f>\notin R^{K}, w \models f(\neg p)$. Hence it's possible that $w \models \mathrm{J}^{\mathrm{P}}(p) \& \mathrm{~J}^{\mathrm{D}}(p) \&$ $\neg p$.

(QED)

Less formally: $\mathrm{JUST}^{\mathrm{P}}$ and $\mathrm{JUST}^{\mathrm{D}}$ aren't factive since they require that the target proposition has to be known in some possible world, while SAFETY requires that one doesn't falsely believe a relevant proposition in any of the closest worlds. Since the world at which $p$ is known need not be among the worlds closest to the world in

\footnotetext{
18 The counterpart function $f$ must be restricted in order to avoid obvious counterexamples. For instance, it cannot be the case that $f(p \& p)=p \& p$ and $f(p)=\neg p$. Otherwise SAFETY wouldn't be closed even under conjunction elimination (Williamson, 2009a, p. 24). Due to lack of space I will not go into the question how $f$ should be restricted.
} 
which $\mathrm{S}$ is justified to believe that $p, p$ can be false while the subject justified to believe that $p^{19}$. Hence the following inference schemas are invalid:

$$
\begin{aligned}
& \mathrm{J}^{\mathrm{P}}(p) \rightarrow(p) \\
& \mathrm{J}^{\mathrm{D}}(p) \rightarrow(p)
\end{aligned}
$$

Since justification isn't factive, justification doesn't entail knowing, unlike on some knowledge-first accounts (Sutton, 2005; Williamson, forthcoming).

It's easy to see that doxastic justification entails propositional justification. After all, $R^{P}$ has access to all the worlds that $R^{D}$ has access to. Therefore, if $w \models \exists<w$, $w^{*}>\in R^{D}, w^{*} \models \mathrm{K}(p)$ then $w \models \exists\left\langle w, w^{*}>\in R^{P}, w^{*}=\mathrm{K}(p)\right.$. Since $R^{D}$ doesn't necessarily have access to all the worlds that $R^{P}$ has access to, propositional justification doesn't entail doxastic justification. $S$ might not believe the target proposition, or might believe it in a way that isn't knowledge conducive in any world, even though $\mathrm{S}$ has a knowledge-conducive way of believing the proposition available to her. Therefore $\mathrm{J}^{\mathrm{D}}(p) \rightarrow \mathrm{J}^{\mathrm{P}}(p)$ is a valid inference schema, while $\mathrm{J}^{\mathrm{P}}(p) \rightarrow \mathrm{J}^{\mathrm{D}}(p)$ isn't.

A plausible constraint on a theory of justification is that knowledge entails justification. On MAJ knowledge entails both propositional and doxastic justification.

Proof For a reductio suppose that $w \models \mathrm{K}(p) \& \neg \mathrm{J}^{\mathrm{D}}(p) . w \models \neg \mathrm{J}^{\mathrm{D}}(p)$ only if $w \models \neg \exists<w$, $w^{*}>\in R^{D}, w^{*} \models \mathrm{K}(p)$. By reflexivity of $R^{D},\left\langle w, w>\in R^{D}\right.$. Since $w \models \mathrm{K}(p)$, $w \models \exists\left\langle w, w^{*}\right\rangle \in R^{D}, w^{*} \models \mathrm{K}(p) \& \neg \exists<w, w^{*}>\in R^{D}, w^{*} \models \mathrm{K}(p)$. Contradiction! Therefore $\mathrm{K}(p) \rightarrow \mathrm{J}^{\mathrm{D}}(p)$. Since $\mathrm{J}^{\mathrm{D}}(p) \rightarrow \mathrm{J}^{\mathrm{P}}(p), \mathrm{K}(p) \rightarrow \mathrm{J}^{\mathrm{P}}(p)$.

An interesting property that justification shares with SAFETY is that it doesn't iterate trivially. The fact that $\mathrm{S}$ is justified to believe that $p$ doesn't entail that she is justified to believe that she is justified to believe that $p$.

Proof Suppose that $\mathrm{S}$ is propositionally justified to believe that $p$ at $w$. That's, $w \models$ $\exists\left\langle w, w^{*}>\in R^{P}, w^{*}=\mathrm{K}(p)\right.$. For $\mathrm{S}$ to be propositionally justified to believe that she is propositionally justified to believe that $p$ to be true at $w$, it must be the case that $w \models \exists<w, w^{*}>\in R^{P}, w^{*} \models \mathrm{K}\left(\mathrm{J}^{\mathrm{P}}(p)\right) . \mathrm{J}^{\mathrm{P}}(p) \rightarrow \mathrm{J}^{\mathrm{P}}\left(\mathrm{J}^{\mathrm{P}}(p)\right)$ is false just in case it's possible that $w \models \exists<w, w^{*}>\in R^{P}, w^{*} \models \mathrm{K}(p) \& \forall<w, w^{*}>\in R^{P}, w^{*}=$ $\neg \mathrm{K}\left(\mathrm{J}^{\mathrm{P}}(p)\right)$. Suppose that $W$ contains three worlds, $w, w^{*}, w^{* *}$. Suppose that $w^{*}=$ $\mathrm{K}(p)$. That is, $\forall<w^{*}, w^{* *}, f>\in R^{K}, w^{* *}=f(p) . w \models \mathrm{K}\left(\mathrm{J}^{\mathrm{P}}(p)\right)$ is true just in case $\forall<w, w^{*}, f>\in R^{K}, w^{*}=f\left(\mathrm{~J}^{\mathrm{P}}(p)\right)$. Suppose that $\left\langle w, w^{* *}, f>\in R^{K}\right.$ and that $\mathrm{J}^{\mathrm{P}}(q)$ is false at $w^{* *}$, while $f\left(\mathrm{~J}^{\mathrm{P}}(p)\right)$ maps at to $\mathrm{J}^{\mathrm{P}}(q)$ at $w^{* *}$. Since $f\left(\mathrm{~J}^{\mathrm{P}}(p)\right)$ maps to a false proposition at a $R^{K}$ accessible world, $\mathrm{J}^{\mathrm{P}}(p)$ isn't known at $w$. An analogous proof can be given for the claim that $\mathrm{S}$ doesn't know that she is justified to believe that $p$ at $w^{*}$ nor at $w^{* *}$. Therefore, it's possible to know that $p$ without it being possible to know one is justified to believe that $p$.

(QED)

Hence the following inference schemas are invalid:

19 Thanks to Nick Hughes for discussion. 


$$
\begin{aligned}
\mathrm{J}^{\mathrm{P}}(p) & \rightarrow \mathrm{J}^{\mathrm{P}}\left(\mathrm{J}^{\mathrm{P}}(p)\right) \\
\mathrm{J}^{\mathrm{D}}(p) & \rightarrow \mathrm{J}^{\mathrm{D}}\left(\mathrm{J}^{\mathrm{D}}(p)\right)
\end{aligned}
$$

Less formally ${ }^{20}$ : Knowledge requires that the subject doesn't end up with a relevantly similar false belief in any of the closest cases. Propositional justification requires merely that the proposition whose justificatory status we evaluate amounts to knowledge in some possible world. This entails that it's possible to be justified to believe that $p$, even though one couldn't have known some other proposition, $q$, that's similar to $p$, since one could easily have mistakenly believed a proposition that's similar to $q$, but not similar to $p$. Since similarity isn't a transitive notion, one's knowledge of $p$ need not be threatened by one's ignorance of $q$.

Another property that justification shares with knowledge is non-luminosity. The fact that $\mathrm{S}$ is justified in believing that $p$ doesn't entail that $\mathrm{S}$ is in a position to know that she is justified in believing that $p$. If it did, the following inference schemas would be valid:

$$
\begin{aligned}
\mathrm{J}^{\mathrm{D}}(p) & \rightarrow \mathrm{P}^{\mathrm{K}}\left(\mathrm{J}^{\mathrm{D}}(p)\right), \\
\mathrm{J}^{\mathrm{P}}(p) & \rightarrow \mathrm{P}^{\mathrm{K}}\left(\mathrm{J}^{\mathrm{P}}(p)\right),
\end{aligned}
$$

where ' $\mathrm{P}^{\mathrm{K}}$, denotes that ' $\mathrm{S}$ is in a position to know'. Being in a position to know that $p$ is factive and requires that there's a close case where one knows that $p$ (Williamson, 2000, p. 128). $\mathrm{J}^{\mathrm{D}}(p) \rightarrow \mathrm{P}^{\mathrm{K}}\left(\mathrm{J}^{\mathrm{D}}(p)\right)$ fails for the same reason why justification doesn't iterate. In order for $\mathrm{J}^{\mathrm{D}}(p)$ to be true at $w \mathrm{~S}$ must believe that $p$ in a way that yields knowledge that $p$ in some world $w^{*}$. In order for $\mathrm{P}^{\mathrm{K}}\left(\mathrm{J}^{\mathrm{D}}(p)\right)$ to be true at $w$ there must be a world $w^{*}$ where $\mathrm{S}$ knows that $\mathrm{J}^{\mathrm{D}}(p) \cdot \mathrm{K}\left(\mathrm{J}^{\mathrm{D}}(p)\right)$ is true at $w^{*}$ iff: $\forall<w^{*}, w^{* *}, f>\in R^{K}, w^{* *}=f\left(\mathrm{~J}^{\mathrm{D}}(p)\right)$. Knowledge requires a margin of error: in all of the closest cases where you believe a similar proposition that you actually believe you end up with a true belief. Justification doesn't require this kind of margin. $\mathrm{S}$ can be justified in believing that $p$ even if there's a close case where $\mathrm{S}$ believes falsely that $q$, where $p$ and $q$ are similar propositions. The fact that $\mathrm{S}$ must know that $p$ in $w^{*}$ in order for $\mathrm{J}^{\mathrm{D}}(p)$ to be true at $w$ doesn't entail that $\mathrm{J}^{\mathrm{D}}(\mathrm{p})$ would be known at any accessible world. It might very well be the case that there's a proposition that is similar to $\mathrm{J}^{\mathrm{D}}(p)$, namely $\mathrm{J}^{\mathrm{D}}(q)$, and that there's some case, $w^{* *}$, that's close to $w^{*}$ where $\mathrm{S}$ believes that $\mathrm{J}^{\mathrm{D}}(q)$ while $\mathrm{J}^{\mathrm{D}}(q)$ is false at $w^{* *}$. In other words, the fact that one is justified to believe that $p$ in $w$, doesn't entail that there would be a case $w^{*}$, such that in all cases that are closest to $w^{*}$, one doesn't believe a false proposition that is relevant when determining whether one knows that one is justified in believing that $p$ in $w^{*}$. Therefore $\mathrm{J}^{\mathrm{D}}(p)$ can be true in $w$ even if there's no case $w^{*}$ where $\mathrm{S}$ is safe from error in believing $\mathrm{J}^{\mathrm{D}}(p)$. Luminosity fails. It's worth noting that this argument is distinct from Williamson's (2000, pp. 96-98) antiluminosity argument. Those who have some qualms with that argument might be

$\overline{{ }^{20} \text { One can substitute } \mathrm{J}^{\mathrm{P}} \text { for } \mathrm{J}^{\mathrm{D}} \text { in the above proof for the same result. }}$ 
more inclined to accept that justification isn't a luminous condition on the above grounds.

Earlier we noted that SAFETY is closed under $\mathrm{MPC}^{\mathrm{K}}$. Assuming then that knowledge is closed under $\mathrm{MPC}^{\mathrm{K}}$, one might wonder whether justification is similarly closed. Consider the following multi-premise closure principle for propositional justification:

MPC $^{\mathrm{P}}$ : If $\mathrm{S}$ is propositionally justified in believing that $p_{1}, \ldots, p_{\mathrm{n}}$, and $p_{1}, \ldots, p_{\mathrm{n}}$ logically entail $q, \mathrm{~S}$ is propositionally justified in believing that $q$.

As it turns out, this principle is invalid. This is because $\mathrm{MPC}^{\mathrm{P}}$ entails a form of logical omniscience but JUST ${ }^{\mathrm{P}}$ doesn't. The fact that $\mathrm{S}$ is propositionally justified to believe $p_{1}, \ldots, p_{\mathrm{n}}$, doesn't entail that there would be a way of believing $q$ that's available to $\mathrm{S}$, such that $\mathrm{S}$ could come to know $q$. This is for two reasons. Firstly, it might simply be the case that $q$ is too complex and there's no way for $\mathrm{S}$ to believe that $q$. Secondly, the inference from $p_{1}, \ldots, p_{\mathrm{n}}$ to $q$ might be beyond S's capabilities. Even if my current body of knowledge would logically entail the truth of Goldbach's conjecture I couldn't believe that Goldbach's conjecture is true in a knowledge-conducive way.

These reasons for the failure of $\mathrm{MPC}^{\mathrm{P}}$ are somewhat tedious. The more interesting reason why it fails is that one can be justified in believing a set of claims that is logically inconsistent. ${ }^{21}$ To see this, suppose that $\{p, q\}$ constitutes a logically inconsistent set. Even though $p$ and $q$ are inconsistent, it might be true that $\mathrm{S}$ has a way of believing that $p$ that yields knowledge that $p$ in some world, and that $\mathrm{S}$ has a way of believing that $q$ that yields knowledge that $q$ in some other world. Since the worlds where $\mathrm{S}$ knows that $p$ and where $\mathrm{S}$ knows that $q$ can be distinct, $\mathrm{S}$ can be propositionally justified in believing each member of a set of inconsistent propositions. But since $\{p, q\}$ logically entails $p \& q$, and $p \& q$ isn't true in any possible world in virtue of being jointly inconsistent, $S$ cannot have a way of knowing $p \& q$. MPC ${ }^{\mathrm{P}}$ fails.

A similar argument could be given to refute a multi-closure principle that was formulated for doxastic justification. It would appear then that the connection between justification and knowledge falls apart when it comes to closure. Knowledge is closed but justification isn't. At this point those who have argued that justification isn't closed under multi-premise closure might be prematurely congratulating themselves. Many have argued that justification isn't closed under multi-premise closure since one can be justified in believing that one's lottery ticket is a loser on the basis of the odds involved. ${ }^{22}$ Since in a fair lottery all of the tickets have the same probability of winning, one should be justified in believing of each ticket that it's a loser on the basis of the odds involved. If justification was closed under multi-premise closure one could then be justified in believing that all the

\footnotetext{
${ }^{21}$ See Heylen (2016) for the argument 'that being in a position to know' isn't closed under logical entailment. The argument below owes much to his work.

22 See Kyburg (1961) for the original lottery paradox. His solution is to reject closure.
} 
tickets are losers. But given that one knows that the lottery is fair one of the tickets is bound to win, and one has justification to believe this. But then one would be justified in believing an all-out contradiction; namely that all of the tickets are losers and that one of them isn't a loser. Therefore multi-premise closure for justification fails. Preface-style considerations have likewise been used to argue that one can be justified in believing a set of claims, all the while not being justified in believing that all of the claims are true. ${ }^{23}$ Many of these authors think that justification requires a sufficiently high probability on one's evidence that one's belief is true. The above considerations would seem to vindicate such reasoning, but the urge to draw that conclusion should be resisted.

While $\mathrm{MPC}^{\mathrm{P}}$ proves to be invalid, and hence justification isn't closed under logical entailment, multi-premise closure is valid for a restricted set of propositions. Crucially, the kind of cases that lie at the center of the debate as to whether justification is closed under multi-premise closure, deal with propositions that belong to this restricted set.

Call any set of propositions $\left\{p_{1}, \ldots, p_{\mathrm{n}}\right\}$ for which it applies that each of its members can be known simultaneously by one subject Moore-consistent. ${ }^{24}$ That is, $\left\{p_{1}, \ldots, p_{\mathrm{n}}\right\}$ is Moore-consistent for $\mathrm{S}$ if and only if there's possible world where $\mathrm{S}$ knows $p_{1}, \ldots, p_{\mathrm{n}}$. The following multi-premise closure principle is then valid for propositional justification:

$\mathrm{MPC}^{\mathrm{MC}}$ : If $\mathrm{S}$ is propositionally justified in believing that $p_{1}, \ldots, p_{\mathrm{n}}$, and $p_{1}, \ldots$, $p_{\mathrm{n}}$ are Moore-consistent for $\mathrm{S}$ and logically entail $q$, and there's a way of believing $q$ on the basis of competent deduction from $p_{1}, \ldots, p_{\mathrm{n}}$ available for $\mathrm{S}$, then $q$ is propositionally justified for S.

It's easy to see that $\mathrm{JUST}^{\mathrm{P}}$ is closed under MPC ${ }^{\mathrm{MC}}$. Since the set of premises is guaranteed to be known in some world, and $\mathrm{MPC}^{\mathrm{MC}}$ requires that $\mathrm{S}$ has a way of believing the conclusion on the basis of the premises, the conclusion must be known in some world where it's believed on the basis of the premises. By restricting our attention to sets of propositions that are Moore-consistent, we guarantee that there's going to be some world where all of the premises are true and knowable at the same time by the subject. Since the Moore-consistent set logically entails the conclusion, and the subject is required to believe the conclusion by competently deducing it from the known premises, her belief in the conclusion must be safe as well. ${ }^{25}$

\footnotetext{
23 See Mackinson (1965) for the preface paradox.

24 I'd like to thank Julien Dutant for the term and discussion on this point.

25 This line of thinking assumes that $\mathrm{MPC}^{\mathrm{K}}$ is valid for knowledge. If SAFETY is sufficient for knowledge $\mathrm{MPC}^{\mathrm{K}}$ is valid for knowledge. Of course, $\mathrm{MPC}^{\mathrm{K}}$ could be valid for knowledge even if SAFETY doesn't give the sufficient conditions for knowledge, since whatever conditions knowledge required in addition to SAFETY need not make MPC $^{\mathrm{K}}$ invalid. Note that unlike clairvoyance, deduction isn't intuitively a bad way of forming beliefs. Hence, whatever condition $x$ in addition to SAFETY rules out clairvoyant-style cases, we have no prima facie reason to think that $x$ would be incompatible with $\mathrm{MPC}^{\mathrm{K}}$.
} 
One might argue that introducing a multi-premise closure principle that is restricted to Moore-consistent propositions is clearly an ad hoc move. But MPC ${ }^{\mathrm{MC}}$ isn't ad hoc. The idea that knowledge is closed under known entailment supports $\mathrm{MPC}^{\mathrm{MC}}$ over unrestricted closure principles. This is because $\mathrm{MPC}^{\mathrm{K}}$ is also restricted to Moore-consistent propositions. Otherwise the subject wouldn't be able to know the premises that are inserted to $\mathrm{MPC}^{\mathrm{K}}$. Those who think that justification is closed under multi-premise closure in virtue of the fact that knowledge is so closed, should be inclined to hold that the closure principles should be as similar as they possibly can be.

Secondly, one might wonder why we should care if justification turned out to be closed under $\mathrm{MPC}^{\mathrm{MC}}$ ? The answer is that the cases that are used to put pressure on the idea that justification is closed under multi-premise closure deal with Mooreconsistent propositions. Consider for example the preface paradox: An author has just finished a book. She has meticulously researched every claim that she made in the book, and has excellent evidence for each claim. Therefore, she is justified in believing of each claim that she made in the book, that it's correct. But she knows that even the best researchers make mistakes, and that every book written on the subject so far has included a few incorrect claims. In a display of intellectual humility, she apologizes in the preface for any incorrect claims that she might have made.

In the preface paradox it's stipulated that the author is justified in believing of each claim she made that it's correct. That's $\mathrm{J}^{\mathrm{D}}\left(p_{1}\right), \ldots, \mathrm{J}^{\mathrm{D}}\left(p_{\mathrm{n}}\right)$ where the book contains $n$ claims. If justification is closed under multi-premise closure then the author should be justified in believing that all of her claims are correct: $\mathrm{J}^{\mathrm{D}}\left(\left(p_{1}\right)\right.$ \& $\left.\ldots, \&\left(p_{\mathrm{n}}\right)\right)$. But it would seem that she is also justified in believing that not all of the claims are correct: $\mathrm{J}^{\mathrm{D}} \neg\left(\left(p_{1}\right) \& \ldots, \&\left(p_{\mathrm{n}}\right)\right)$. By another application of multi-premise closure we get the absurd: $\mathrm{J}^{\mathrm{D}}\left(\left(p_{1}\right) \& \ldots, \&\left(p_{\mathrm{n}}\right)\right) \& \neg\left(\left(p_{1}\right) \& \ldots, \&\left(p_{\mathrm{n}}\right)\right)$. Given that multi-premise closure leads to absurd consequences, we should abandon it, or so the argument goes.

What kind of solution does MAJ offer to this paradox? Note that nothing in the case description hints that the $n$ claims aren't Moore-consistent. Therefore, the author can be justified in believing that all of the claims are correct: $\mathrm{J}^{\mathrm{D}}\left(\left(p_{1}\right) \& \ldots, \&\right.$ $\left.\left(p_{\mathrm{n}}\right)\right) .{ }^{26}$ Moreover, there's no prima facie reason to think that the author couldn't know that the book contains at least one incorrect claim. While high evidential probability alone doesn't suffice to make a belief safe, the author doesn't have to draw on purely probabilistic considerations when forming the belief. She might know that many experts disagree with her findings or she might have heard someone she trusts saying that the book contains an incorrect claim. Therefore she can be justified in believing that the book contains an incorrect claim: $\mathrm{J}^{\mathrm{D}} \neg\left(\left(p_{1}\right) \&\right.$ \& , \&

\footnotetext{
${ }^{26}$ Smith (2016) has argued that if one is justified in believing each claim, then one is justified in believing their conjunction. If the conjuncts are less than certain on one's evidence then the evidential probability that the conjunction is true can be maximally close to zero on one's evidence. Therefore, one can be justified in believing propositions that are extremely unlikely to be true given one's evidence. I endorse the same view on this matter. See also Williamson (2009a).
} 
$\left.\left(p_{n}\right)\right) .{ }^{27}$ Note, however, that the author cannot be justified in believing that all of the claims are correct and that one of them is incorrect, since that proposition is unknowable. There's no world where all of the claims are correct and one of them is incorrect. Therefore it's never the case that $\mathrm{J}^{\mathrm{D}}\left(\left(p_{1}\right) \& \ldots, \&\left(p_{\mathrm{n}}\right)\right) \& \neg\left(\left(p_{1}\right) \& \ldots, \&\right.$ $\left.\left(p_{\mathrm{n}}\right)\right)$.

This solution to the preface paradox is particularly satisfying for three reasons. First, it secures the idea that inferences that preserve knowledge cannot fail to preserve justification. If an inference could preserve knowledge without preserving justification, justification could be lost in an inference that yielded knowledge and hence knowledge wouldn't entail justification. Second, it doesn't require that agents in preface-type situations should abandon all their beliefs, or an arbitrary subset of them, and hence it avoids skepticism. Third, it vindicates the intuition that the author is justified in her beliefs, while being justified in believing that she has a false belief. $^{28}$

But one might object that the solution that MAJ provides to the preface paradox entails that a subject can believe with justification a set of propositions that is logically inconsistent, and reject MAJ on those grounds. ${ }^{29}$ It is worth noting that MAJ is hardly the only view of justification or rationality that has this consequence. ${ }^{30}$ Indeed, I think accepting that a subject can believe with justification a set of logically inconsistent propositions is nowadays the mainstream position. However, the view might nevertheless come with some unwanted costs. Olin (2003, pp. 82-83), for instance, argues that it would force us to accept that one can believe with justification a contradiction, and Kaplan (1996, p. 97) argues that deductive arguments would have no epistemic force. These would be dire consequences indeed, but luckily MAJ leads into neither. First, since a contradiction is false in all possible worlds they cannot be known, and hence a belief in a contradiction can never be justified on MAJ. Second, deductive arguments do have epistemic power in many cases. Often we reason from premises that are Moore-consistent, and in such cases MPC ${ }^{\mathrm{MC}}$ is valid. ${ }^{31}$ Olin $(2003$, p. 83) argues also that reductio ad absurdum

\footnotetext{
27 Some authors appear to reject the idea that one could on inductive grounds be justified to believe that the book contains an incorrect claim. See for instance Olin (2003, p. 68). But Backes (2019) and Praolini (2019) have recently put forth preface cases where it is stipulated that the author knows on non-inductive grounds that the set of claims contains an incorrect claim, and doesn't merely seem to have justification to think that it does. In Praolini's case an omniscient referee tells the author that her book manuscript contains one false claim, but annoyingly does not say which claim is false. In Backes' case the subject has ingested a pill that ensures that some of her justified beliefs are in fact false, and she knows that the pill has this effect. Thus rejecting the idea $\mathrm{J}^{\mathrm{D}} \neg\left(\left(p_{1}\right) \& \ldots, \&\left(p_{\mathrm{n}}\right)\right)$ is not an option in all variants of the preface case.

28 Thanks to Maria Lasonen-Aarnio for helpful discussion.

29 Epistemologists who hold that justified beliefs have to be logically consistent include, Pollock (1983), Ryan (1991), Kaplan (1996), and Olin (2003). I would like to thank an anonymous reviewer at Philosophical Studies for inviting me to consider this objection.

30 Foley (1992), Christensen (2004), Fitelson and Easwaran (2015), Worsnip (2016), Littlejohn and Dutant (2020), Engel (forthcoming), and Field (forthcoming) defend the possibility of inconsistent justified beliefs.

31 See Christensen (2004, Ch. 4.3) for a more general argument as to as to why rejecting logical consistency requirements doesn't lead to the rejection of the epistemic force of deductive arguments.
} 
arguments would lack epistemic force, since they work by demonstrating that a set of premises logically imply an inconsistency. But if one can believe with justification a set of propositions that is logically inconsistent, a reductio would not force us to abandon any particular proposition. But even though on MAJ one can be justified to believe a set of propositions that is logically inconsistent, it does not entail that a reductio would have no epistemic force. By carrying out a reductio the author in the preface case can come to know that one of their claims is false. And while this doesn't destroy the justification that they have for any single claim that they made in the book, it does invite them to re-examine the claims they made. Both Field (forthcoming) and Lasonen-Aarnio (2020) observe that recognizing that one has inconsistent beliefs can be epistemically beneficial, since it can be a powerful motivation pay more attention to one's commitments or to seek out further evidence. If in the preface case one were to abandon the belief that one of the claims in the book is false, thus restoring consistency, we would hardly think that the author was epistemically laudable in any sense.

Next, consider the lottery paradox. If we assume per impossibile that lottery propositions can be known there's no reason to think that the set of propositions \{ticket \#1 is a loser, ..., ticket \#n-1 is a loser\} wouldn't be Moore-consistent if the lottery contains $n$ tickets. Hence, if one could be justified in believing that a single ticket is a loser, one could be justified to believe of all but one of the tickets that they are losers. But that would be absurd!

Crucially a belief that this 'ticket is a loser', formed solely on the basis of the odds involved, can never be justified, because such beliefs could never amount to knowledge. ${ }^{32}$ Given that the lottery was fair, there's a very close world where one's ticket wins. In that world one would still have believed that one's ticket is a loser, and hence one doesn't know that one's ticket is a loser. Since in the lottery case there's no way to know that one's ticket is a loser on the basis of the odds involved, one cannot be justified in believing that one's ticket is a loser on the basis of the odds involved.

Let me highlight one more feature of justification as it's here understood. On the suggested account, Moore-paradoxical propositions are never justified. A Mooreparadoxical proposition is of the form ' $p$ but $\mathrm{I}$ do not believe that $p$ '. Such propositions (or utterances) are generally thought to be paradoxical, but it's not easy to explain their paradoxical status given that they aren't logically inconsistent in any obvious way. It might very well be the case that $p$ is true and that I do not believe that $p$. In fact this is true of most true propositions!

To prove that Moore-paradoxical propositions are never justified assume for a reductio that $w \models \mathrm{J}^{\mathrm{P}}(p \& \neg \mathrm{B}(p))$. That's: $\exists<w, w^{*}>\in R^{P}, w^{*} \models \mathrm{K}(p \& \neg \mathrm{B}(p))$. If $w^{*} \models \mathrm{K}(p \& \neg \mathrm{B}(p))$ then $w^{*} \models \mathrm{K}(p), \mathrm{K}(\neg \mathrm{B}(p))$. Since knowledge is factive $\mathrm{K}(\neg \mathrm{B}(p))$ entails $\neg \mathrm{B}(p)$. Given that knowledge entails belief, $\mathrm{K}(p)$ entails $\mathrm{B}(p)$. Therefore, in $w^{*} \models \mathrm{B}(p)$ and $\neg \mathrm{B}(p)$ are true. Contradiction! Therefore, Moore-paradoxical propositions are never justified.

\footnotetext{
32 Nelkin (2000) has argued that the solution to the lottery paradox that concerns justification should parallel the solution of the paradox if it's formulated in terms of knowledge. MAJ does just that.
} 


\section{Comparisons}

In this section I briefly compare MAJ with the knowledge-first accounts of justification proposed by Bird (2007), Ichikawa (2014) and Rosenkranz (2017). These accounts bear most similarity to MAJ, and hence I focus on them. ${ }^{33}$

Bird (2007) and Ichikawa $(2014,2017)$ have argued that justification is potential knowledge. According to Bird, a subject $\mathrm{S}$ who is in mental states $\mathrm{M}$, and then forms a judgment, is justified in so judging if and only if there's some world where $\mathrm{S}$ has the same mental states $\mathrm{M}$ and then forms a corresponding judgment that yields knowledge (Bird, 2007, p. 84). According to Ichikawa, S's belief is justified if and only if " $\mathrm{S}$ has a possible counterpart, alike to $\mathrm{S}$ in all relevant intrinsic respects, whose corresponding belief is knowledge" (Ichikawa, 2014, p. 194). These views are similar to mine in that they understand justification as potential knowledge.

Views that understand justification in terms of potential knowledge have a problem with necessarily false propositions. Since necessarily false propositions aren't true in any world, they cannot be known in any world, and hence one cannot be justified in believing them. Both Bird (2007, p. 87) and Ichikawa (2014, p. 194; 2017) claim that they are able to dodge this problem since the belief that amounts to knowledge in the possible world need not be the same belief, but can be its counterpart. ${ }^{34} A$ belief $B_{1}$ is taken to be the counterpart of belief $B_{2}$ just in case $B_{2}$ is at most a minor variation on the content of $\mathrm{B}_{1}$, and $\mathrm{B}_{1}$ and $\mathrm{B}_{2}$ are produced by the same mental dispositions and capacities (Bird, 2007, p. 87).

But allowing for 'content variation' when it comes to justification will make it extremely hard to deliver plausible formal constraints on justification. ${ }^{35}$ For instance, since a necessary falsehood is a contradiction, the fact that $\mathrm{S}$ believes a contradiction doesn't entail that her belief is unjustified. As a result, Bird and Ichikawa cannot secure the idea that Moore-paradoxical beliefs are never justified. While it's true that a belief of the form ' $p$ but I do not believe that $p$ ' never amounts to knowledge, it might have a counterpart that can be known. The counterpart could be ' $p$ * but I do not believe that $p$ '. Since this proposition isn't knowledge inconsistent it might be known at some world, and hence renders the Mooreparadoxical ' $p$ but I do not believe that $p$ ' justified on Bird's and Ichikawa's account. By the same token Bird and Ichikawa cannot endorse the solution that MAJ offers to the preface paradox. By allowing for content variation they open up the possibility that the author is justified in believing the all-out contradiction that all of the claims in the book are correct and that one of them is incorrect.

MAJ is hardly the only view that delivers the result that necessarily false belief are never justified. For example, the accounts of justification proposed by Smith (2010, 2016), Littlejohn (2011), Williamson (forthcoming), Sutton (2005), Rosenkranz (2017), Praolini (2019) and Steglich-Petersen (2013) deliver the same

\footnotetext{
33 For other knowledge-first accounts of justification that don't equate justification with knowledge, see Reynolds (2013), Miracchi (2015), Kelp (2016), Silva (2017) and Lasonen-Aarnio (forthcoming).

34 Ichikawa (2014) has argued that Bird is not able to deal with the problem of necessarily false propositions if content-externalism is true.

35 I borrow this term from Paterson (forthcoming).
} 
result. Furthermore, brands of evidentialism that understand the evidential supportrelation in probabilistic terms also yield the same result, since the probability of a necessary falsehood is 0 on any body of evidence. ${ }^{36}$ None of these accounts is rejected in virtue of delivering this result. As Titelbaum writes "What is often viewed as a bug of formal epistemologies is necessary for their best features" (2015, p. 257).

While MAJ delivers the result that one is never justified in believing necessarily false propositions it's possible to give an error-theoretic explanation of the goodness of some such beliefs. Suppose that $S$ comes to believe a necessarily false mathematical claim by using a calculator that happens to malfunction. While S's belief isn't justified on MAJ, a knowledge-centric normative framework can still explain the goodness of her belief. After all, the way in which $\mathrm{S}$ formed her belief would usually result in knowledge. That is, she behaves like someone who would believe a proposition only if they were justified in believing it. Hence she satisfies a derivative norm that the norm of belief generates, and we can explain the goodness of her belief via her conformity to this derivative norm (Williamson, forthcoming). She is clearly better off than a wishful thinker, who doesn't conform even to this derivative norm. ${ }^{37}$

Here's another reason to favour MAJ over the views of Bird and Ichikawa. MAJ is more general, in that it covers both propositional and doxastic justification, whereas Bird and Ichikawa account only for doxastic justification, and it's not easy to see how they could extend their frameworks to propositional justification. For example, since Ichikawa holds that justification supervenes on the internal, and since beliefs are at least partially internal, no one who knows that $p$ is the counterpart of someone who doesn't have the relevant belief. Since S can be propositionally justified in believing that $p$ without actually believing that $p, \mathrm{~S}$ will not have any intrinsic counterpart who knows that $p .^{38}$

Rosenkranz (2017) offers the following definition of propositional justification in terms of 'being in a position to know' and negation, where ' $\mathrm{P}^{\mathrm{K}}$, stands for 'one is in a position to know': $\mathrm{J}^{\mathrm{P}}(p) \leftrightarrow \neg \mathrm{P}^{\mathrm{K}}\left(\neg \mathrm{P}^{\mathrm{K}}(p)\right)$. In other words, to be justified in believing that $p$ is to not be in a position to know that one isn't in a position to know that $p$. The framework under which Rosenkranz operates is highly idealized and subjects are always in a position to know all logical truths and the logical consequences of what they are in a position to know. Hence, for any necessarily false proposition $p$, subjects are always in a position to know that they aren't in a

\footnotetext{
36 The account of evidential probability offered by Williamson (2000) doesn't entail that the evidential probability of all necessarily false propositions is 0 . However, it does entail that logically equivalent propositions have the same probability because probability is insensitive to differences between logically equivalent propositions (Williamson, 2000, p. 212). Because necessarily false propositions are logically equivalent, all such propositions have the same evidential probability. Since practically all rational subjects will assign probability 0 to a known contradiction, all necessary falsehoods will have the evidential probability 0 for such subjects.

37 It is worth to note that even if the problem of necessarily false propositions was deemed severe enough to reject MAJ as an account of justification, I would still have demonstrated important formal properties of potential knowledge. This in itself would be a significant philosophical result.

38 I'd like to thank Niall Paterson for discussions about Bird's and Ichikawa's views.
} 
position to know that $p$, and for any necessary truth $q$, subjects are never in a position to know that they aren't in a position to know that $q$. Therefore, subjects are never justified in believing what is necessarily false and are always justified in believing what is necessarily true. Furthermore, subjects never fail to be in a position to know a proposition because of physical or psychological deficiencies (Rosenkranz, 2017, pp. 318-319). While Rosenkranz's subjects are idealized to the extreme, this shouldn't stop us from drawing interesting lessons about the structure of 'being in a position to know'. It is, however, unclear what kind of ramifications Rosenkranz's account would have for subjects like us, who are flawed in innumerable ways.

MAJ differs significantly from the view developed by Rosenkranz. His account validates two principles that are often favoured by internalists, and rejected by externalists. Crucially these principles are invalid on MAJ.

$$
\begin{gathered}
\mathrm{JJ}: \mathrm{J}^{\mathrm{P}}(p) \rightarrow \mathrm{J}^{\mathrm{P}}\left(\mathrm{J}^{\mathrm{P}}(p)\right) \\
\text { Luminosity: } \mathrm{J}^{\mathrm{P}}(p) \rightarrow \mathrm{P}^{\mathrm{K}}\left(\mathrm{J}^{\mathrm{P}}(p)\right)
\end{gathered}
$$

Since I'm convinced by Williamson's (2000, pp. 96-98) anti-luminosity argument I take this to be a good reason to reject Rosenkranz's account of justification. Rosenkranz, however, endorses Luminosity, and therefore my aversion to Luminosity will not make him flinch. If we want to stay neutral on Luminosity and JJ we need a better argument.

Here is a potential counterexample to $\mathrm{J}^{\mathrm{P}}(p) \leftrightarrow \neg \mathrm{P}^{\mathrm{K}}\left(\neg \mathrm{P}^{\mathrm{K}}(p)\right)$. The counterexample establishes that if one is in an extremely bad epistemic situation, where it's contingently true that one cannot know any contingent truth, then one is justified to believe any contingently true proposition.

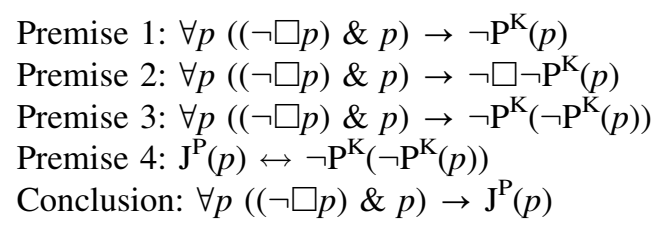

Less formally: Suppose that S's epistemic environment is so hostile that she isn't in a position to know any contingently true proposition, and that this is a contingent fact (premises 1 and 2). Since it's contingently true that $S$ isn't in a position to know any contingent proposition, $S$ isn't in a position to know that she isn't in a position to know $p$, where $p$ is any contingently true proposition (premise 3). Given $\mathrm{J}^{\mathrm{P}}(p) \leftrightarrow \neg \mathrm{P}^{\mathrm{K}}\left(\neg \mathrm{P}^{\mathrm{K}}(p)\right), \mathrm{S}$ is justified to believe any contingently true proposition (premise 4 and the conclusion). But that's absurd! Rather, if $\mathrm{S}$ is in such a bad position she shouldn't be justified in believing anything. It's natural to think that if your epistemic circumstances are better, then you have more justification than you would have if your epistemic circumstances were worse. According to Rosenkranz the opposite is true. If you end up in the worst possible epistemic environment all contingently true propositions are propositionally justified for you. Note that Rosenkranz's idealized subjects can find themselves in such a situation, since he 
acknowledges that a subject may fail to be in a position to know a contingent proposition, since being in a position to know requires safety $(2017$, p. 319$) .{ }^{39}$

Ultimately, I think that Rosenkranz can deal with this kind of counterexample by idealizing his subjects even more. Given that the subjects he is focusing on are already extremely idealized I do not see a principled reason why he couldn't do so. The reason that his view might be susceptible to the above counterexample is, however, not the reason why I think we ought to prefer MAJ. The reason to prefer MAJ is that it's applicable to subjects who aren't idealized to the extreme. We want a theory of justification that can be applied to subjects like us.

I have demonstrated how MAJ differs from some of its main rivals. I think that MAJ does well in comparison, but I will leave the ultimate verdict to the reader.

\section{Conclusions}

I put forth a novel account of justification in terms of knowledge. On MAJ, to be justified is to be in an epistemic position in which one could know that $p$. I highlighted many of the formal principles that justification abides by, and showed how it relates to knowledge. I contrasted the view with some of its main rivals. The point was not to demonstrate that MAJ is superior to other accounts, but merely to make room for it. That said, there are many important questions relating to justification that I have not been able to cover that I wish to engage with in the future.

Acknowledgements I would like to thank Giada Fratantonio, Daniel Drucker, Maria Lasonen-Aarnio, and Niall Paterson for extensive written comments and discussion. Thanks also to Bob Beddor, Jessica Brown, Julien Dutant, Andreas Fjellstad, Nils Franzén, Simon Goldstein, Daniel Greco, Nick Hughes, Fabian Hundertmark, Maria Hämeen-Anttila, Antti Kauppinen, Markus Lammenranta, Vili Lähteenmäki, Sanna Mattila, Lisa Miracchi, Andrew Mueller, Jennifer Nagel, Christian Nimtz, Mika Oksanen, Gabriel Sandu, Paul Silva, Martin Smith, Tuukka Tanninen, Luca Zanetti, two anonymous reviewers at Philosophical Studies, and the audiences at the universities of Bologna, Helsinki, Umea and the Goethe Epistemology Meeting for insightful comments that improved this paper. This project has received funding from the European Research Council (ERC) under the European Union's Horizon 2020 research and innovation programme under grant agreement No 758539.

Funding Open access funding provided by University of Helsinki including Helsinki University Central Hospital.

Open Access This article is licensed under a Creative Commons Attribution 4.0 International License, which permits use, sharing, adaptation, distribution and reproduction in any medium or format, as long as you give appropriate credit to the original author(s) and the source, provide a link to the Creative Commons licence, and indicate if changes were made. The images or other third party material in this article are included in the article's Creative Commons licence, unless indicated otherwise in a credit line

\footnotetext{
39 One might object that we could be in such a bad epistemic situation. Perhaps we're always in a position to know some contingent propositions that feature an indexical, such as 'I'm here'. But this objection is easily tackled. We can simply restrict the argument to some set of contingent propositions, which one intuitively isn't justified to believe. These could be propositions about future weather conditions or the amount of trout in the lochs of Scotland. Thanks to Niall Paterson and Maria LasonenAarnio for helpful discussion.
} 
to the material. If material is not included in the article's Creative Commons licence and your intended use is not permitted by statutory regulation or exceeds the permitted use, you will need to obtain permission directly from the copyright holder. To view a copy of this licence, visit http:// creativecommons.org/licenses/by/4.0/.

\section{References}

Anscombe, G. E. M. (1962). On sensations of position. Analysis, 22(3), 55-58. https://doi.org/10.1093/ analys/22.3.55\%JAnalysis

Backes, M. (2019). A bitter pill for closure. Synthese, 196, 3773-3787.

Bird, A. (2007). Justified judging. Philosophy and Phenomenological Research, 74(1), 81-110. https:// doi.org/10.1111/j.1933-1592.2007.00004.x

Bogardus, T. (2014). Knowledge under threat. Philosophy and Phenomenological Research, 88(2), 289-313. https://doi.org/10.1111/j.1933-1592.2011.00564.x

Bonjour, L. (1980). Externalist theories of empirical knowledge. Midwest Studies in Philosophy, 5, 53-73.

Christensen, D. (2004). Putting logic in its place. Oxford University Press.

Comesana, J. (2006). A well-founded solution to the generality problem. Philosophical Studies, 129(1), 27-47.

Dretske, F. (2005). The case against closure. In M. Steup \& E. Sosa (Eds.), Contemporary debates in epistemology (pp. 13-25). Blackwell.

Engel, M. (forthcoming). Lotteries, knowledge, and inconsistent belief: Why you know your ticket will lose. Synthese, 1-31.

Feldman, R. (1995). In defence of closure. The Philosophical Quarterly (1950-), 45(181), 487-494. https://doi.org/10.2307/2220312

Feldman, R., \& Conee, E. (1985). Evidentialism. Philosophical Studies, 48(1), 15-34. https://doi.org/10. 1007/bf00372404

Field, C. (forthcoming). Embracing incoherence. In N. Hughes (Ed.), Epistemic dilemmas (pp. 1-29): Oxford University Press.

Firth, R. (1978). Are epistemic concepts reducible to ethical concepts? In A. I. Goldman \& J. Kim (Eds.), Values and morals: Essays in Honor of William Frankena, Charles Stevenson, and Richard Brandt (pp. 215-229). Springer, Netherlands.

Fitelson, B., \& Easwaran, K. (2015). Accuracy, coherence and evidence. Oxford Studies in Epistemology, 5, 61-96.

Foley, R. (1992). The epistemology of belief and the epistemology of degrees of belief. American Philosophical Quarterly, 29(2), 111-124.

Foley, R. (2012). When is true belief knowledge? Princeton University Press.

Gettier, E. (1963). Is justified true belief knowledge? Analysis, 23, 121-123.

Hawthorne, J. (2005). The case for closure. In M. Steup \& E. Sosa (Eds.), Contemporary debates in epistemology (pp. 26-43). Oxford: Blackwell.

Heylen, J. (2016). Being in a position to know and closure. Thought: A Journal of Philosophy, 5(1), 63-67. https://doi.org/10.1002/tht3.194

Hirvelä, J. (2017). Is it safe to disagree? Ratio, 30, 305-321.

Hirvelä, J. (2019a). Global safety: How to deal with necessary truths. Synthese, 196(3), 1167-1186. https://doi.org/10.1007/s11229-017-1511-z

Hirvelä, J. (2019b). Knowing without having the competence to do so. Thought: A Journal of Philosophy, 8(2), 110-118. https://doi.org/10.1002/tht3.411

Hirvelä, J. (2020a). How to stay safe while extending the mind. Synthese, 197(9), 4065-4081. https://doi. org/10.1007/s11229-018-01920-0

Hirvelä, J. (2020b). No safe haven for the virtuous. Episteme, 17(1), 48-63.

Hirvelä, J., \& Paterson, N. (2021). Need knowing and acting be SSS-Safe? Thought: A Journal of Philosophy, 10(2), 127-134. https://doi.org/10.1002/tht3.487

Ichikawa, J. (2014). Justification is potential knowledge. Canadian Journal of Philosophy, 44(2), 184-206. https://doi.org/10.1080/00455091.2014.923240

Ichikawa, J. (2017). Contextualising knowledge: Epistemology and semantics. Oxford University Press. 
Kaplan, M. (1996). Decision theory as philosophy. Cambridge University Press.

Kelp, C. (2016). Justified belief: Knowledge first-style. Philosophy and Phenomenological Research, 93(1), 79-100. https://doi.org/10.1111/phpr.12272

Kornblith, H. (2008). Knowledge needs no justification. In Q. Smith (Ed.), Epistemology: New essays (pp. 5-24). Oxford University Press.

Kvanvig, J. L. (2003). Propositionalism and the perspectival character of justification. American Philosophical Quarterly, 40(1), 3-17.

Kyburg, H. E. (1961). Probability and the logic of rational belief. Wesleyan University Press.

Lasonen-Aarnio, M. (2010a). Is there a viable account of well-founded belief? Erkenntnis (1975-), 72(2), 205-231.

Lasonen-Aarnio, M. (2010b). Unreasonable knowledge. Philosophical Perspectives, 24(1), 1-21.

Lasonen-Aarnio, M. (2020). Enkrasia or evidentialism? Learning to love mismatch. Philosophical Studies, 177(3), 597-632. https://doi.org/10.1007/s11098-018-1196-2

Lasonen-Aarnio, M. (forthcoming). Competent failure and victims of deceit. In F. Dorsch \& J. Dutant (Eds.), The new evil demon problem. Oxford: Oxford Univeristy Press.

Levi, I. (2012). Deductive closure. Synthese, 184, 493-499.

Lewis, D. (1979). Attitudes de dicto and de se. The Philosophical Review, 88(4), 513-543.

Littlejohn, C. (2011). Justification and the truth connection. Cambridge University Press.

Littlejohn, C. (2018). The right in the good: A defense of teleological non-consequentialism. In: Epistemic consequentialism. Oxford: Oxford University Press.

Littlejohn, C., \& Dutant, J. (2020). Justification, knowledge, and normality. Philosophical Studies, 177(6), 1593-1609.

Mackinson, D. (1965). The paradox of the preface. Analysis, 25(6), 205-207.

Miracchi, L. (2015). Competence to know. Philosophical Studies, 172, 29-56.

Nelkin, D. K. (2000). The lottery paradox, knowledge, and rationality. The Philosophical Review, 109(3), 373-409. https://doi.org/10.2307/2693695

Neta, R., \& Rohrbaugh, G. (2004). Luminosity and the safety of knowledge. Pacific Philosophical Quarterly, 85(4), 396-406. https://doi.org/10.1111/j.1468-0114.2004.00207.x

Nozick, R. (1981). Philosophical explanations. Oxford University Press.

Olin, D. (2003). Paradox. Mcgill-Queen's University Press.

Paterson, N. (forthcoming). Safety and necessity. Erkenntis, 1-17.

Pollock, J. L. (1983). Epistemology and probability. Synthese, 55(2), 231-252. https://doi.org/10.1007/ bf00485070

Praolini, F. (2019). No justificatory closure without truth. Australasian Journal of Philosophy. https://doi. org/10.1080/00048402.2018.1564059

Pritchard, D. (2005). Epistemic luck. Oxford University Press.

Pritchard, D. (2012). Anti-luck virtue epistemology. Journal of Philosophy, 109(3), 247-279.

Reynolds, S. L. (2013). Justification as the appearance of knowledge. Philosophical Studies, 163(2), 367-383. https://doi.org/10.1007/s11098-011-9820-4

Rosenkranz, S. (2017). The structure of justification. Mind, 127(506), 629-629. https://doi.org/10.1093/ mind/fzx039\%JMind

Ryan, S. (1991). The preface paradox. Philosophical Studies, 64(3), 293-307. https://doi.org/10.1007/ BF00365003

Silva, P. (2015). On doxastic justification and properly basing one's beliefs. Erkenntnis, 80(5), 945-955. https://doi.org/10.1007/s10670-014-9690-1

Silva, P. (2017). Knowing how to put knowledge first in the theory of justification. Episteme, 14(4), 393-412.

Smith, M. (2010). What else justification could be. Nous, 44(1), 10-31. https://doi.org/10.1111/j.14680068.2009.00729.x

Smith, M. (2016). Between probability and certainty - what justifies belief. Oxford University Press.

Sosa, E. (1999). How must knowledge be modally related to what is known? Philosophical Topics, 26(1/ 2), 373-384.

Sosa, E. (2015). Judgment and agency. Oxford University Press.

Srinivasan, A. (2020). Radical externalism. The Philosophical Review, 129(3), 395-431.

Steglich-Petersen, A. (2013). Truth as the aim of epistemic justification. In T. Chan (Ed.), The aim of belief. Oxford University Press.

Sutton, J. (2005). Stick to what you know. Nous, 39(3), 359-396. https://doi.org/10.1111/j.0029-4624. 2005.00506.x 
Sutton, J. (2007). Without justification. Cambridge, MA: Bradford Books.

Sylvan, K. (2017). Knowledge as a non-normative relation. Philosophy and Phenomenological Research. Titelbaum, M. G. (2015). Rationality's fixed point (or: in defense of right reason). In T. Gendler \& J. Hawthorne (Eds.), Oxford studies in epistemology (Vol. 5, pp. 253-294). Oxford University Press.

Turri, J. (2010). On the relationship between propositional and doxastic justification. Philosophy and Phenomenological Research, 80(2), 312-326. https://doi.org/10.1111/j.1933-1592.2010.00331.x

Williamson, T. (2000). Knowledge and its limits. Oxford University Press.

Williamson, T. (2009a). Probability and danger. The Amherst Lecture in Philosophy, 4, 1-35.

Williamson, T. (2009b). Reply to John Hawthorne and Maria Lasonen-Aarnio. In P. Greenough \& D. Pritchard (Eds.), Williamson on knowledge (pp. 313-329). Oxford University Press.

Williamson, T. (forthcoming). Justifications, excuses, and sceptical scenarios. In F. Dorsch \& J. Dutant (Eds.), The new evil demon. Oxford: Oxford University Press.

Vogel, J. (1990). Are there counterexamples to the closure principle? In M. Roth \& G. Ross (Eds.), Doubting: Contemporary perspectives on skepticism. Dordrecht: Kluwer.

Worsnip, A. (2016). Belief, credence, and the preface paradox. Australasian Journal of Philosophy, 94(3), 549-562.

Zagzebski, L. (1994). The inescapability of gettier problems. Philosophical Quarterly, 44(174), 65-73.

Publisher's Note Springer Nature remains neutral with regard to jurisdictional claims in published maps and institutional affiliations. 